Laser Chem., 1999, Vol. 19, pp. $321-324$

Reprints available directly from the publisher Photocopying permitted by license only
(C) 1999 OPA (Overseas Publishers Association) N.V. Published by license under the Harwood Academic Publishers imprint, part of The Gordon and Breach Publishing Group.

Printed in India.

\title{
VIBRATIONAL RELAXATION PROCESS OF POLYATOMIC MOLECULES ADSORBED IN ZEOLITES
}

\author{
KEN ONDA*, MICHIO YAGINUMA, AKIHIDE WADA, \\ KAZUNARI DOMEN and CHIAKI HIROSE
}

Research Laboratory of Resources Utilization, Tokyo Institute of Technology, 4259 Nagatsuta, Midori-ku, Yokohama 226, Japan

(Received 11 April 1997)

The vibrational relaxation lifetimes of the $\mathrm{CO}$ stretching mode of $\mathrm{Cr}(\mathrm{CO})_{6}$ and $\mathrm{Mo}(\mathrm{CO})_{6}$ adsorbed in the cage of the HY, DY and NaY-type zeolites were measured at various temperature by pump-probe method using picosecond infrared laser pulses. It was shown by comparing the lifetimes that the accepting modes include both the vibrational modes of the metal carbonyl and those associated with the cations on the zeolite surface. The analysis of the temperature dependence of the lifetimes revealed that the number of the excited accepting modes are four with their energy lying around $500 \mathrm{~cm}^{-1}$.

Keywords: Vibrational relaxation; metal carbonyl; zeolite; infrared; picosecond; solid surface

\section{INTRODUCTION}

Species adsorbed in zeolite offers a good model system for the study of vibrational relaxation process on a solid surface [1-7]. In the present study, the vibrational relaxation lifetimes of the $\mathrm{CO}$ stretching mode of $\mathrm{Cr}(\mathrm{CO})_{6}$ and $\mathrm{Mo}(\mathrm{CO})_{6}$ adsorbed on the HY, DY and NaY-type zeolites were measured at various temperature by pump-probe method using picosecond infrared laser pulses. Here the term AY-type $(\mathrm{A}=\mathrm{H}, \mathrm{D}$ and $\mathrm{Na})$ implies that the structure of the zeolite is $\mathrm{Y}$-type

${ }^{*}$ Corresponding author. 
and $\mathrm{A}^{+}$cation is incorporated on a surface of the cage. Since the metal carbonyl is physisorbed at the cation site and the system is appropriate for the investigation of the mechanism of vibrational relaxation from a polyatomic molecule to a solid surface through a weak interaction.

\section{EXPERIMENTAL}

The zeolite powder was pressed to a self-supporting disk and was placed in a quartz IR cell evacuated by an oil rotary pump to $\sim 10^{-3}$ Torr. The disk was exposed at room temperature to the vapor of metal carbonyls and the atmosphere inside the cell was replaced by 60 Torr of carbon monoxide. The temperature of the cell was controlled in the region from $100 \mathrm{~K}$ to $900 \mathrm{~K}$ by flowing liquid $\mathrm{N}_{2}$ and resistive heating. The lifetimes were measured by the pump-probe method using picosecond IR pulses. The frequency-tunable (1400$4000 \mathrm{~cm}^{-1}$ ) picosecond IR pulses were generated by the combination of optical parametric generation and amplification (OPG/OPA) and difference-frequency generation (DFG) [8].

\section{RESULTS AND DISCUSSION}

The obtained lifetimes at $110 \mathrm{~K}$ are listed in Table I. According to the theory of vibrational relaxation derived by Nitzan and Jortner $[9,10]$, vibrational lifetime at low temperature is dependent on the anharmonic coupling between the excited mode and accepting modes. The amplitude of the anharmonic coupling is determined by the combination of the excited and accepting modes. Thus, the difference in the lifetimes for HY and DY-type zeolites suggests that the vibrational mode including the cation on the surface is one of the accepting modes

TABLE I Lifetimes (ps) of CO stretching mode of metal carbonyls adsorbed in the cage of NaY, HY and DY-type zeolites at $110 \mathrm{~K}$

\begin{tabular}{lccc}
\hline & NaY-type & HY-type & DY-type \\
\hline $\mathrm{Cr}(\mathrm{CO})_{6}$ & $140(12)$ & $87(6)$ & $74(7)$ \\
$\mathrm{Mo}(\mathrm{CO})_{6}$ & $150(10)$ & $70(4)$ & $53(5)$ \\
\hline
\end{tabular}


because the only difference between the HY and DY-type zeolites is the mass of the cation. On the other hand, the difference of the lifetimes for the two metal carbonyls indicates that the vibrational modes also inside the metal carbonyl is included in the set of accepting modes.

The rate constants of vibrational relaxation, i.e., inverse of the lifetimes, are plotted as a function of temperature in Figure 1. The above-mentioned theory of vibrational relaxation also predicts that the temperature dependence of the rate constant $(\gamma)$ for a single
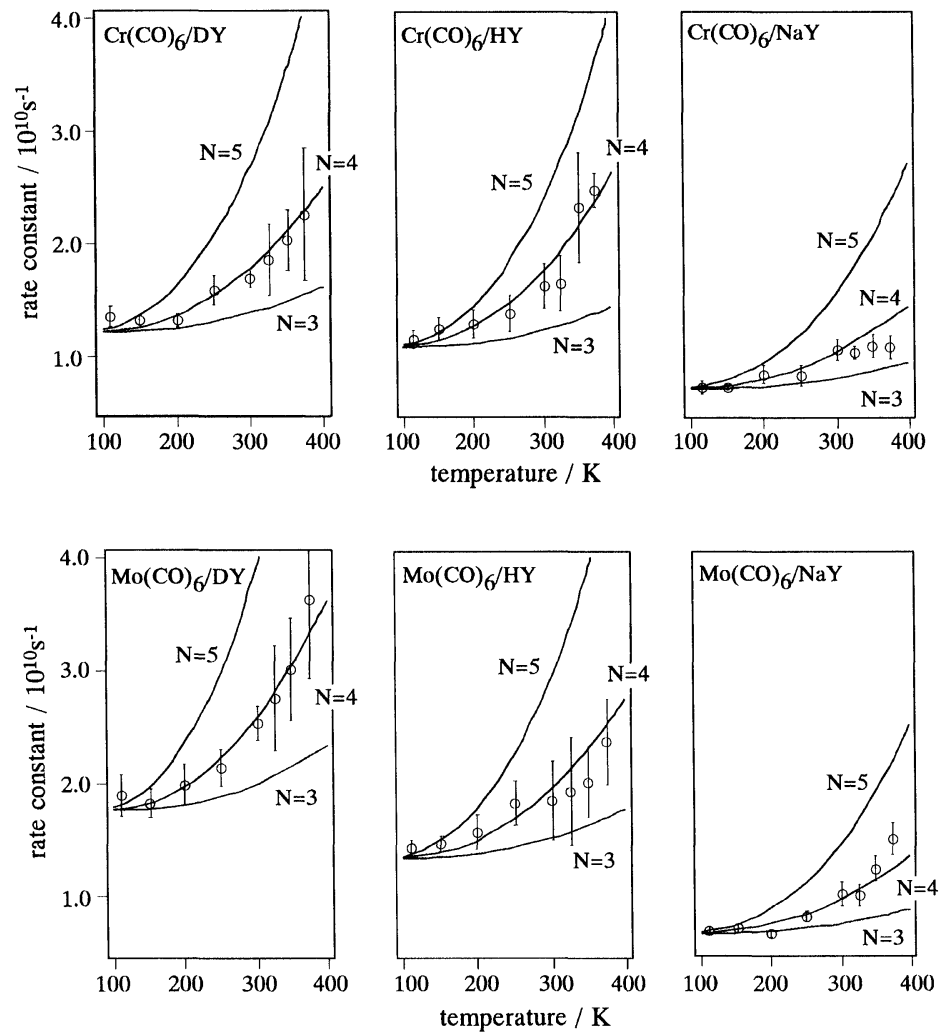

FIGURE 1 Temperature dependence of the rate constant for the vibrational relaxation of the $\mathrm{CO}$ stretching mode of $\mathrm{Cr}(\mathrm{CO})_{6}$ and $\mathrm{Mo}(\mathrm{CO})_{6}$ adsorbed on $\mathrm{DY}, \mathrm{HY}$ and $\mathrm{NaY}-$ type zeolites. Open circles with error bars represent experimental values and solid curves were calculated using Eq. (1) assuming that number of quanta excited at the accepting modes are three $(\mathrm{N}=3)$, four $(\mathrm{N}=4)$ and five $(\mathrm{N}=5)$. 
relaxation path is expressed as,

$$
\gamma=\gamma_{0} \frac{\exp \left(\hbar \omega_{0} / k T\right)-1}{\prod_{\nu}\left[\exp \left(\hbar \omega_{\nu} / k T\right)-1\right]},
$$

where $\gamma_{0}$ is the rate constant at low temperature, and $\omega_{0}$ and $\omega_{v}$ are the vibrational frequencies of the excited and the accepting modes, respectively. The solid curves in Figure 1 are the results calculated by assuming that all accepting modes have the same frequencies. $\mathrm{N}=3,4$ and 5 in Figure 1 represent the quanta of the excited accepting mode. Although the absolute values of $\gamma$ differ by the system, temperature-dependent features are so similar and are in good agreement with the lines calculated for $N=4$. This indicates that the number of quanta excited at accepting modes of main relaxation path is four and the energy lies around $500 \mathrm{~cm}^{-1}$ independent of the system.

\section{References}

[1] Fujino, T., Furuki, M., Kashitani, M., Onda, K., Kubota, J., Kondo, J. N., Wada, A., Domen, K., Hirose, C., Wakabayashi, F., Ishida, M., Goto, F. and Kano, S. S. (1996). J. Chem. Phys., 105, 279.

[2] Kashitani, M., Fujiono, T., Fukuyama, K., Kubota, J., Kondo, J. N., Wada, A., Domen, K., Hirose, C., Wakabayashi, F., Ishida, M., Goto, F. and Kano, S. S. (1996). J. Chem. Phys., 105, 6665.

[3] Domen, K., Kano, S. S., Fujino, T., Furuki, M., Kashitani, M., Kubota, J., Kondo, J. N., Wada, A., Ishida, M., Goto, F., Wakabayashi, F. and Hirose, C. (1996). Surf. Sci., 363, 397.

[4] Bonn, M., Bakker, H. J., Kleyn, A. W. and van Santen, R. A. (1996). J. Phys. Chem., 100, 15301.

[5] Brugmans, M. J. P., Bakker, H. J. and Langendijk, A. (1996). J. Chem. Phys., 104, 64.

[6] Bonn, M., Brugmans, M. J. P., Kleyn, A. W., van Santen, R. A. and Bakker, H. J. (1996). Phys. Rev. Lett., 76, 2440.

[7] Bonn, M., Brugmans, M. J. P., Klen, A. W., van Santen, R. A. and Bakker, H. J. (1996). J. Chem. Phys., 105, 3431.

[8] Zhang, J. Y., Huang, J. Y., Shen, Y. R. and Chen, C. (1993). J. Opt. Soc. Am. B., 10, 1758.

[9] Nitzan, A. and Jortner, J. (1973). Mol. Phys., 25, 713.

[10] Nitzan, A., Mukamel, S. and Jortner, J. (1974). J. Chem. Phys., 60, 3929. 